\title{
A Classification of Multidimensional Open Data for Urban Morphology
}

\author{
Alexandros Alexiou $^{* 1}$, Alex Singleton ${ }^{\dagger 1}$, and Paul A. Longley ${ }^{\ddagger 2}$ \\ ${ }^{1}$ Department of Geography and Planning, University of Liverpool, \\ Roxby Building, Liverpool L69 7ZT, UK \\ ${ }^{2}$ Department of Geography, University College London, Gower Street, \\ London WC1E 6BT, UK
}

\begin{abstract}
Identifying socio-spatial patterns through geodemographic classification has proven utility over a range of disciplines. While most of these spatial classification systems include a plethora of socio-economic attributes, there is arguably little to no input regarding attributes of the built environment or physical space, and their relationship to socio-economic profiles within this context have not been evaluated in any systematic way. This research explores the generation of neighbourhood characteristics and other attributes using a geographic data science approach, taking advantage of the increasing availability of such spatial data from open data sources. We adopt a SOM (Self-Organizing Maps) methodology to create a classification of Multidimensional Open Data for Urban Morphology (MODUM) and test the extent to which this output systematically follows conventional socio-economic profiles. Such an analysis can also provide a simplified structure of the physical properties of geographic space that can be further used as input to more complex socio-economic models.
\end{abstract}

KEYWORDS: geodemographics, open data, neighbourhood, SOM (Self-Organizing Maps)

\section{Introduction}

Geodemographics is a field of quantitative geography that engages in the analysis and classification of populations into discrete classes based on socio-economic and built environment characteristics of small-area geography. Simply put, geodemographics is the "analysis of people by where they live" (Sleight, 1997, p. 16). Such classifications have demonstrated utility over a range of public and private sector applications (Longley, 2005; Longley and Goodchild, 2008; Reibel, 2011; Singleton and Spielman, 2013). A geodemographic analysis is essentially a data reduction methodology that aggregates populations, so that correlations between sub-populations can be drawn upon with ease. It involves the process of producing key statistics of a particular area, on the basis of the characteristics of its residents and their contexts.

*a.alexiou@liverpool.ac.uk

†alex.singleton@liverpool.ac.uk

‡p.longley@ucl.ac.uk 
Geodemographic applications were initially developed as a strategy in order to analyse and systematically document socio-spatial segregation. The associated data reduction methods were established in the 1970s (Webber, 1978), although a wider review and interpretation would extend right back to the 'human ecology' studies from the Chicago School of Sociology in the 1920s (Burgess, 1925), social area analysis in the 1950s (Shevky and Bell, 1955) and the factorial ecologies of the 1970s (Janson, 1980). Despite the fact that geodemographics has evolved considerably over the years (Singleton and Spielman, 2013), the conceptual background of geodemographics is still wedded to the principle that people tend to align themselves with the behaviour and aspirations of the local communities in which they live. The inferential nature of the aggregations relies on the notion of societal homophily, or in other words, that "birds of a feather flock together" (Harris et al., 2005). As such people who live close by (e.g. in the same neighbourhood) are more likely to have commonalities in attributes and behaviours than a randomly selected group of people.

Although geodemographic frameworks can capture a wide set of input attributes, current classification systems typically include little to no input of explicitly spatial attributes regarding the built and physical attributes of neighbourhoods. There is, however, an abundance of variables that might be collected on the built forms and relative locations that underpin neighbourhood differentiation. For instance, proximity to certain amenities is important to residential decisions such as transport nodes, parks, retail and healthcare-facilities. There has for example been extensive research into the topic of analysing relationships between accessibility and urban development patterns, (e.g. land use- transportation interaction (LUTI) models); and connectivity has been advanced as a key feature in shaping urban residential dynamics and socio-spatial segregation (Dear, 2002). Research on residential decisions has also attracted a lot of attention over the years, particularly through hedonic modelling. While most of the relevant research focuses on the importance of work location (Van Ommeren et al., 1999; Renkow and Hoover, 2000), there is strong evidence that certain demographic groups favour some relative locations over others, and that the nature and configuration of the local built environment and land-use characteristics is also relevant (Hui et al., 2007). For instance, individuals with children often favour greenspace and recreational opportunities nearby, while those without children prefer smaller residences that offer closer proximity to central services (Colwell et al., 2002). Other characteristics may impact the area as unfavourable, negative externalities, such as high-speed roads or railway tracks within the vicinity of the neighbourhood (Parkes et al., 2002). It is unclear how exactly such characteristics impact upon residential decisions as there are many synergies involved across life cycles (Kim et al., 2005). For instance, moderate proximity $(200 \mathrm{~m}$ to $300 \mathrm{~m})$ to a green space may mitigate negative effects of noise pollution (Gidlof-Gunnarsson and Ohrstrom, 2007).

Some census variables reflect limited built environment characteristics, for instance housing type and population densities. For classification systems that have been developed entirely from census variables, such as the publicly open ONS (Office of National Statistics) Output Area Classification (OAC) for 2011, attributes such as density can however be misleading; the arbitrary nature of the geographic extents of the administrative areas for which population measurements are offered renders comparisons between the physical features ineffective. Other proprietary geodemographic classifications, such as Mosaic by Experian (Nottingham, UK) and Acorn by CACI (London, UK) include some measures of relative location (CACI, 2013; Experian, 2014). However, to what precisely these attributes pertain, how they are used in the clustering process and the weight they are assigned in the final classification remains obscure, because of the commercial sensitivities that are inherent in 'black box' commercial solutions 
(Singleton and Longley, 2009).

In this paper, we test whether specific and multidimensional urban morphologies systematically correspond with socio-economic characteristics at the neighbourhood level. In order to identify and analyse such attribute patterns, we adopt a geodemographic approach, which involves the creation of a classification for a national extent, based upon clustering at the small area level. In essence, we try to identify the physical and built environment characteristics that might be used to supplement neighbourhood typologies.

\section{Open Data Inputs}

This research captures a variety of physical attributes collected for a small-area geography, and in order to enhance reproducibility, replication and extension these inputs are assembled from Open Data sources (Singleton et al., 2016). We produce a classification at the 2011 UK Census Output Area level for the 181,408 Output Areas (OAs) that make up England and Wales. One of the main providers of geographical data for England and Wales is the national mapping agency Ordnance Survey (OS), and there are many datasets available within their repository, with varying degrees of granularity, depending on whether they are publicly accessible or available for purchase. As this paper focuses on Open Data sources, we use OS Open Map Local, the most recent and detailed open OS vector data product currently available (Ordnance Survey, 2015). However, within different contexts, such data might also be supplemented by other national mapping agency data, or perhaps alternative sources such as OpenStreetMap (www.openstreetmap.org). The OS vector data product provides a variety of information including outlines of buildings, street network with hierarchy, railways, woodland areas, surface water and important functional sites.

While the OS Open Map - Local provides the main source of these data, there were a few other sources within England and Wales deemed of utility. These included data about listed buildings and historic parks and gardens supplied by the Historic England Archive (https://services.historicengland.org.uk/NMRDataDownload/) which is regularly updated (November 2015 update used here) and also under Open Data License. For beautiful Wales, the corresponding provider is the Cadw heritage organisation, (available through the UK data Service, https:/data.gov.uk/dataset/listed-buildings-in-wales-gis-point-dataset), although the data are slightly outdated (September 2011). Commercial buildings for local retail centres were identified using data from the Local Data Company, an Open version of which is available through the ESRC Consumer Data Retail Centre. Finally, we included aggregated data on housing type from the 2011 Census supplied by the Office for National Statistics (ONS). Unfortunately, there are currently no Open Data available on building age or height.

Table 1 below summarizes the range of inputs used to derive measures featured in this analysis.

Table 1. Description of the spatial dataset compiled.

\begin{tabular}{l|l}
\hline Variable Name & Variable Description \\
\hline D1: OA Boundaries & $\begin{array}{l}\text { 181,408 Output Area boundaries, as defined by the } 2011 \text { Census. All other data were } \\
\text { spatially joined with their respective OAs that they fall into (data features were split } \\
\text { when falling into more than one OA). }\end{array}$ \\
\hline D1: Buildings & $\begin{array}{l}12,878,666 \text { Building objects represented as polygons. Note that these areas do not } \\
\text { represent individual households. }\end{array}$ \\
\hline D2: Road Network & $\begin{array}{l}\text { Road network is represented as line segments, approximate to the road centre. The } \\
\text { categories include 'Motorway', 'Primary Road', 'A Road', 'B Road', 'Minor Road', }\end{array}$ \\
\hline
\end{tabular}




\begin{tabular}{|c|c|}
\hline & $\begin{array}{l}\text { 'Pedestrianised Street', 'Local Street' and 'Private Road Publicly Accessible', as well as } \\
\text { their 'Collapsed Dual Carriageway' counterparts. }\end{array}$ \\
\hline D3: Woodland & Areas of trees represented as polygons, described as coniferous and non-coniferous. \\
\hline $\begin{array}{l}\text { D4: Functional Sites / } \\
\text { Important Buildings }\end{array}$ & $\begin{array}{l}\text { 120,677 Building polygons that can be found within functional sites. They are categorised } \\
\text { into themes such as Air Transport, Education, Medical Care, Road Transport and Water } \\
\text { Transport, which are further classified into numerous more discrete classes. }\end{array}$ \\
\hline $\begin{array}{l}\text { D5: Railway Stations } \\
\text { and Tracks }\end{array}$ & $\begin{array}{l}\text { Railway tracks and tunnels represented as lines (in this instance we used tracks only in } \\
\text { the analysis) and Railway Stations defined as points. }\end{array}$ \\
\hline D6: Surface water & $\begin{array}{l}\text { Polygons of surface water. small rivers and streams are represented as lines and were } \\
\text { not included in the dataset. The dataset was also supplemented with 'sea water', derived } \\
\text { from the country's coastline. }\end{array}$ \\
\hline $\begin{array}{l}\text { D7: Registered Historic } \\
\text { Buildings }\end{array}$ & 406,496 listed historic buildings defined as points, which were geolocated. \\
\hline $\begin{array}{l}\text { D8: Registered Parks } \\
\text { and Gardens }\end{array}$ & $\begin{array}{l}\text { 2,007 Polygon features with extents of the parks / gardens, classified as I, II*, or II, from } \\
\text { most to least important. For Wales, the } 372 \text { sites were identified from points from a } \\
\text { "Named Places" dataset and given an approximate } 200 \mathrm{~m} \text { radius. }\end{array}$ \\
\hline D9: Retail Centres & $\begin{array}{l}\text { 1,312 Retail Centres across the England and Wales. There is no recent update for this } \\
\text { dataset which dates back to } 2004 \text {. The centres are only depicted as points and have no } \\
\text { typology attached. We assumed an average radius of } 200 \mathrm{~m} \text { to convert them to areas. }\end{array}$ \\
\hline D10:Housing Type & $\begin{array}{l}\text { Percentage of households that are classified by the Census as Detached, Semi-detached, } \\
\text { Terraced or Flat. }\end{array}$ \\
\hline D11: Population & Population of total persons per OA. \\
\hline
\end{tabular}

The classification presented later was created for Output Areas (LSOAs), and as such the input measures were assembled for this geography. These zones offer advantage over other administrative units in England and Wales since many other socio-economic classifications are offered at the OA level, such as the 2011 ONS Output Area Classification, thus making comparisons possible. Additionally, such geography also allows the incorporation of Census data which are distributed for these units. However, for the range of the derived measures that are described in the remainder of this section, there are problems with this approach. OA borders were designed to maximize within zone homogeneity in population characteristics (population normalization), without regard to the geographical features of the area (Martin et al., 2001; see Figure 1). As such, for proximity based inputs there were challenges about how such measures might be calculated, and to which area they should be attributed.

A similar attempt to create such a dataset was made by the Department for Communities and Local Government in 2005, within the framework of the ONS Neighbourhood Statistics, described as Land Use Statistics. The dataset was described as a generalised land use database aggregated into OAs. The dataset contained estimates of built environment attributes, such as roads, paths, domestic and non-domestic buildings, domestic gardens, water, rail etc. Despite the fact that the proprietary OS Enhanced Basemap was used to create this resource, ONS classified it as experimental, as there were issues of accuracy, mainly arising because only the centroids of features were taken into account in class assignments of aggregations.

To facilitate these methodological shortcomings, we adopted three different types of attribute measures for each OA that related to either two types of proximity measures including adjacency effects or intermediate effects; and additionally direct measures. The lattermost of these are simply attributes captured at the OA level, while the first two assume buildings as the initial unit of analysis which are then later assigned to OAs. Building polygon features serve as observations in this input dataset, and represent homogenous built-up areas which can include one or more households. A graphical representation of the model is described in Figure 2. All of the attributes collated as input across all domains are summarised in Table 2. 

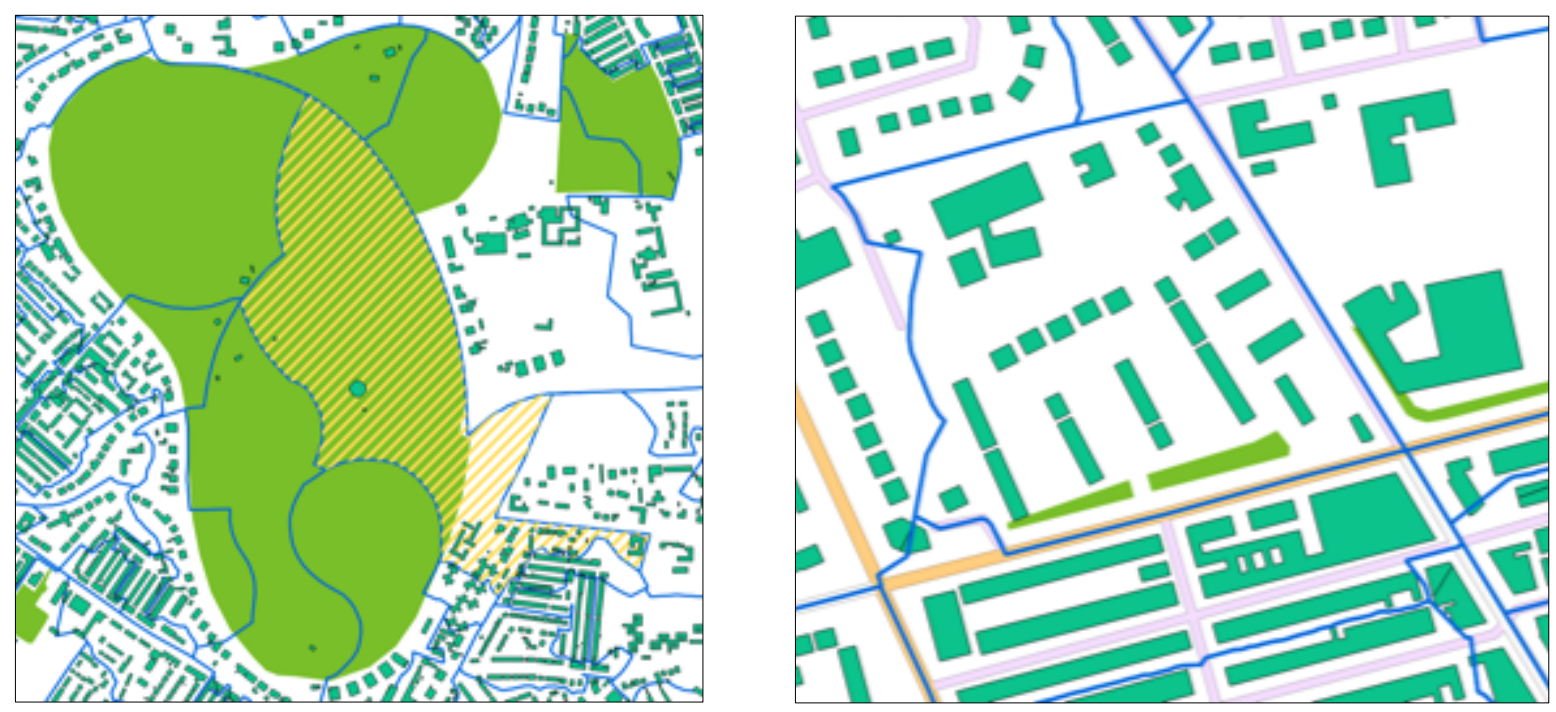

Figure 1. Maps looking at the un-generalised Output Area borders (blue lines) around Sefton Park, Liverpool.

Left: Notice how the area of the park is divided arbitrarily between proximal OAs (yellow hashed line pattern). Right: Output Area borders usually coincide with the street network, making simple street network-to-area assignments impracticable.

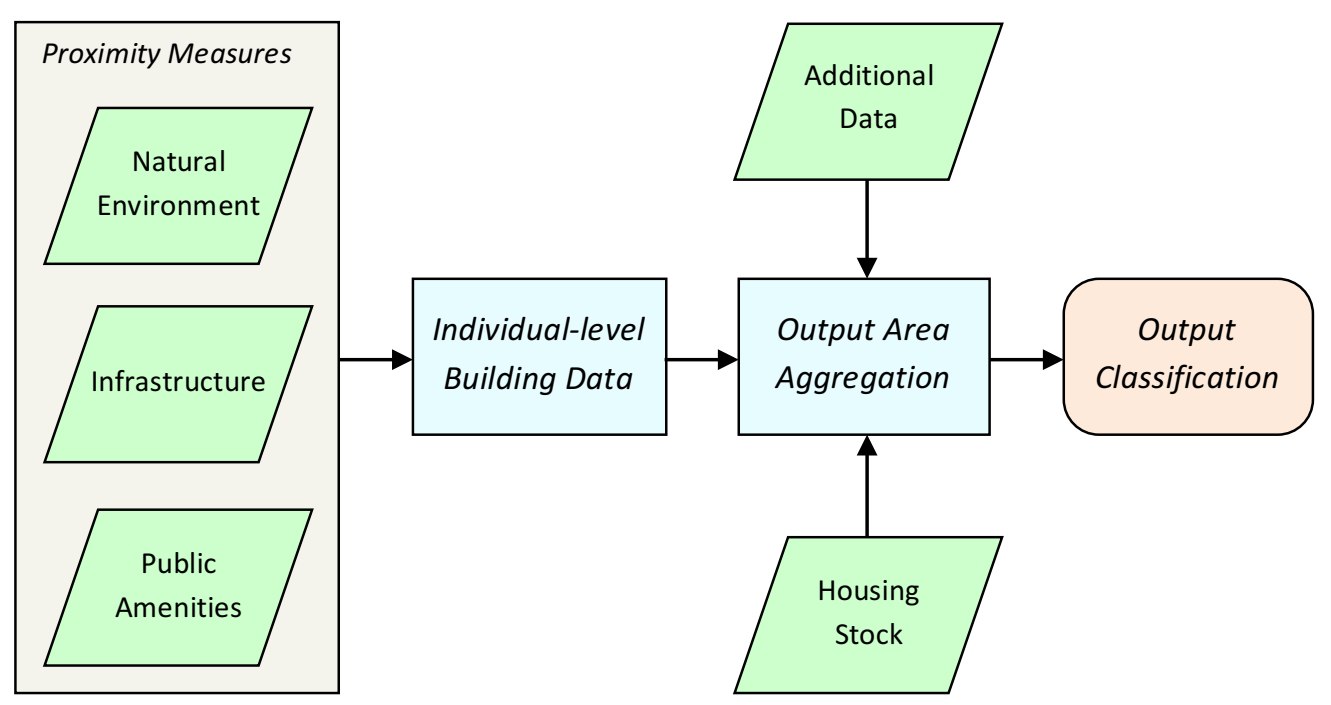

Figure 2. The spatial data model used to process data and produce Output Area inputs to the classification.

For both types of proximity measure, we used a series of spatial queries that identified buildings that fulfil certain criteria, for instance, which buildings are within a set distance of a major 
street? The buildings that met each criterion were then assigned to OA aggregations with weights determined by their attributed area. Thus, within each OA, a ratio of the area of buildings meeting the criteria relative to the total built area was calculated for each of the attributes considered in the analysis. The necessity to differentiate between adjacency and intermediate proximity effects follows the logic that not all built environment characteristics have the same effect, and these effects may vary in scale. For example, when considering the location of a residential property, being adjacent to a very major road might be perceived as having a negative impact, given the noise / pollution associated with increased traffic volumes, whereas being near, but not adjacent to a busy road might be perceived as advantageous, given the enhanced connectivity this might facilitate.

We defined adjacency effects to features measured within $100 \mathrm{~m}$ linear distance, as commonly used in the literature on negative externality effects of built environment features, such as noise or pollution from roads (Rijnders et al., 2001). For intermediate effects a distance of $600 \mathrm{~m}$ was used, on the basis of various western international definitions of "within walking distance". The distance figure generally varies depending on the context of analysis, but distances between $300 \mathrm{~m}$ and $900 \mathrm{~m}$ are considered appropriate for urban features (Hui et al., 2007; Barbosa et al., 2007; Villeneuve et al., 2012; Vale, 2015).

Outside of these distances we assume there are no adjacency or intermediate effects. The delineation of adjacency effects or intermediate effects brings additional practical considerations which relate to the overall density of the built environment features being considered. In common with practice when creating inputs to multidimensional classifications, preference should be for those attributes which in addition to theoretical rationale, also provide useful differentiation between areas (Spielman and Singleton, 2015). For example, in this application, when $600 \mathrm{~m}$ buffers were used for major roads, this resulted in more than $50 \%$ of buildings meeting this criterion, providing only weak differentiation. These tasks were computationally expensive, as the complete dataset contains more than 12.8 million observations (building polygons). Thus the database was pre-processed into regional datasets which were then computed separately within the R coding language.

Finally, there were two further types of direct measures: those which were derived from geographic features, and those which were simple inputs from secondary data. The derived direct measures included listed buildings and cul-de-sacs (dangling segments in the road network). The later of these was defined geocomputationally as the end of a line segment that did not intersect with any other such segment. A sensitivity of $10 \mathrm{~m}$ was applied to this criterion in order to avoid topological errors and intermittent street segments. The results show that such measures can capture specific urban morphologies even at the small-area level as we show in Figure 3.

For the other non-derived direct measures, the variables were simply aggregated directly at the OA level, such as the housing type. Population density was calculated using a ratio of persons per total building area, which potentially would give more accurate results regarding housing conditions. The final OA attributes along with their descriptions are provided in Table 2. 

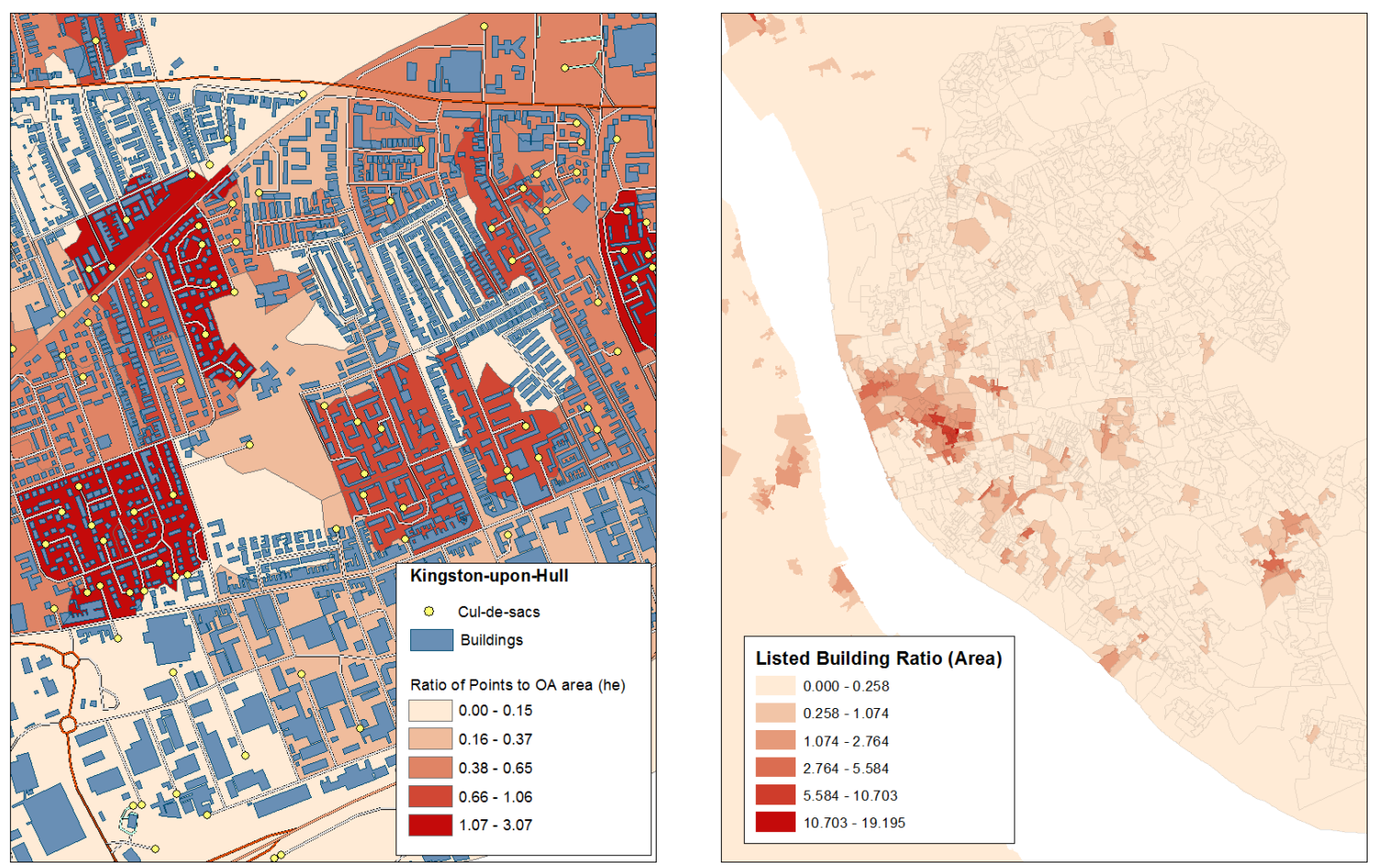

Figure 3. Left: Attribute of Cul-de-sac ratio per OA at Kingston-upon-Hull, Yorkshire. Right: The ratio of listed (registered) buildings per OA area in Liverpool.

Table 2. Built environment attributes used in the classification.

\begin{tabular}{|c|c|}
\hline Variables & Variable Description, Aggregated per OA Code \\
\hline \multicolumn{2}{|l|}{ Adjacent effects } \\
\hline 1. Major Roads & $\begin{array}{l}\text { Percentage of the area of buildings that the centroid is within 100m of a major road to the total } \\
\text { building area. We defined major as those of type "Motorway", "A Road" and "Primary Road". }\end{array}$ \\
\hline 2. Arterial Roads & $\begin{array}{l}\text { Percentage of the area of buildings that their centroid is within } 100 \mathrm{~m} \text { of an arterial road to the } \\
\text { total building area. We defined Arterial roads as those with type "B Road". }\end{array}$ \\
\hline 3. Pedestrian Roads & $\begin{array}{l}\text { Percentage of the area of buildings that their centroid is within } 100 \mathrm{~m} \text { of a pedestrian road or } \\
\text { footway to the total building area. }\end{array}$ \\
\hline 4. Railway Tracks & $\begin{array}{l}\text { Percentage of the area of building units that their centroid is within } 100 \mathrm{~m} \text { of railway tracks, } \\
\text { excluding tunnels to the total building area. }\end{array}$ \\
\hline 5. Woodland Areas & $\begin{array}{l}\text { Percentage of the area of building units that their centroid is within } 100 \mathrm{~m} \text { of woodland features } \\
\text { to the total building area. }\end{array}$ \\
\hline 6. Surface Water & $\begin{array}{l}\text { Percentage of the area of building units that their centroid is within } 100 \mathrm{~m} \text { of surface water } \\
\text { (inland) and seafront (calculated by the distance from the coastal line), but excluding small } \\
\text { rivers and streams, to the total building area. }\end{array}$ \\
\hline \multicolumn{2}{|l|}{ Intermediate effects } \\
\hline 7. Railway Stations & $\begin{array}{l}\text { Percentage of the area of building units that their centroid is within } 600 \mathrm{~m} \text { from the centroid of } \\
\text { a railway station to the total building area. }\end{array}$ \\
\hline 8. Parks \& Gardens & $\begin{array}{l}\text { Percentage of the area of building units that their centroid is within } 600 \mathrm{~m} \text { from the registered } \\
\text { site extents to the total building area. }\end{array}$ \\
\hline 9. Retail Centres & $\begin{array}{l}\text { Percentage of the area of building units that their centroid is within } 600 \mathrm{~m} \text { from the retail centre } \\
\text { centroid plus } 200 \mathrm{~m} \text { to the total building area. }\end{array}$ \\
\hline 10. Schools & $\begin{array}{l}\text { Percentage of the area of building units that their centroid is within } 600 \mathrm{~m} \text { from the sites that } \\
\text { are identified as primary through secondary education to the total building area. }\end{array}$ \\
\hline 11. Higher Education & $\begin{array}{l}\text { Percentage of the area of building units that their centroid is within } 600 \mathrm{~m} \text { from the sites that } \\
\text { are identified as further and higher education to the total building area. }\end{array}$ \\
\hline \multicolumn{2}{|l|}{ Direct measures } \\
\hline 12. Detached Ratio & $\begin{array}{l}\text { Percentage of unshared households that are classified by the } 2011 \text { Census as detached housing } \\
\text { to the total building area. }\end{array}$ \\
\hline 13. Semi-Detached Ratio & $\begin{array}{l}\text { Percentage of unshared households that are classified by the } 2011 \text { Census as semi-detached } \\
\text { housing to the total building area. }\end{array}$ \\
\hline 14. Terraced Ratio & $\begin{array}{l}\text { Percentage of unshared households that are classified by the } 2011 \text { Census as terraced housing } \\
\text { to the total building area. }\end{array}$ \\
\hline
\end{tabular}




\begin{tabular}{|l|l|}
\hline 15. Flat Ratio & $\begin{array}{l}\text { Percentage of unshared households that are classified by the 2011 Census as Flats to the total } \\
\text { building area. }\end{array}$ \\
\hline 16. Density & Ratio of persons to total building area (people/he). \\
\hline 17. Cul-de-sac & Ratio of cul-de-sacs or dead-end road points to the total OA area (points/he). \\
\hline 18. Registered Buildings & Ratio of listed buildings to the total OA area (points/he) \\
\hline
\end{tabular}

\section{A multidimensional classification of the built environment}

Methodologically, our cluster analysis follows a conventional approach as detailed in Harris et al. (2005); however, here we use only built environment data to create the typology. A common clustering technique used in geodemographic analyses is the iterative allocation - reallocation algorithm, known as k-means. Although this algorithm has been used in a variety of geodemographic applications, our dataset is sparsely populated, and k-means is known not to respond well to the non-Gaussian distributions that characterise such datasets (Everitt et al., 2011).

As such, in this framework we adopt the alternative technique of a Self-Organizing Map (SOM). A SOM is an unsupervised classifier that uses artificial neural networks to classify multidimensional observations in two-dimensional space based on their similarities (Kohonen, 2001). A SOM typically organize observations by projecting them onto a plane, and through consecutive iterations finds the best configuration of observations so that every observation is most similar to the others closest to them. Typically, the SOM mapping process employs a lattice of squares or hexagons as the output layer, and the results are therefore easily mapped as they retain their topology. SOMs have many applications in a broad range of fields, from medicine and biology to image analysis and computer science. SOMs have also been tested as an alternative classifier of census data (Spielman and Thill, 2008; Arribas-Bel and Schmidt, 2013) where they seem to perform well for socioeconomic data at the US Census tract scale. Arribas-Bel, Nijkamp and Scholten (2011) have also demonstrated the algorithm capabilities to measure urban sprawl in Europe using a similar attribute set, specifically six variables: connectivity, decentralization, density, scattering, availability of open space and land-use mix, . The technique also has the advantage of not assuming any hypotheses regarding the nature or distribution of the data, and responds well to geographic sensitivity. A further advantage of using a SOM is the capacity to visualise the structure of data values aiding initial data exploration. This feature can be very useful when analyzing datasets such as our built environment measures, where there are little to non a-priori hypotheses on their underlying distribution.

As input to this analysis the dataset comprising the 18 variables described in Table 2 were transformed into z-scores in order to standardise the measures. The majority of the analysis and output production was performed in the R programming language using the "Kohonen" library (Wehrens and Buydens, 2007). More specifically, we adopted a SOM approach to cluster our input dataset using the methodology described by Spielman and Folch (2015). A relatively unexplored built environment classification with too many clusters would be difficult to interpret, so we selected a 4-by-2 hexagonal grid, which produces 8 distinct clusters. We implemented a hexagonal geodesic grid to project results. A geodesic plane forces the cells' relations to "loop" around the edges, while the hexagonal representation is typically favoured over grids, as this configuration benefits from every cell having six immediate neighbours. The other main parameters of the SOM algorithm are the learning rate alpha, which we defined to progress linearly from 0.05 to 0.01 over fifty reconfigurations (updates), and the initial size of the neighbourhood, in this instance a distance chosen in such a way that two-thirds of all distances of the map units fall within the topological extents. The neighbourhood decreases 
linearly during training until the algorithm reaches equilibrium. The algorithm has achieved equilibrium at $\sim 25$ iterations, meaning that no more changes to the observations' configuration were required, with the mean distance to the closest unit in the map at 11.34. Once areas were assigned to clusters, we then implemented a radar plot to map their characteristics on the basis of the input variables as we show in Figure 4.
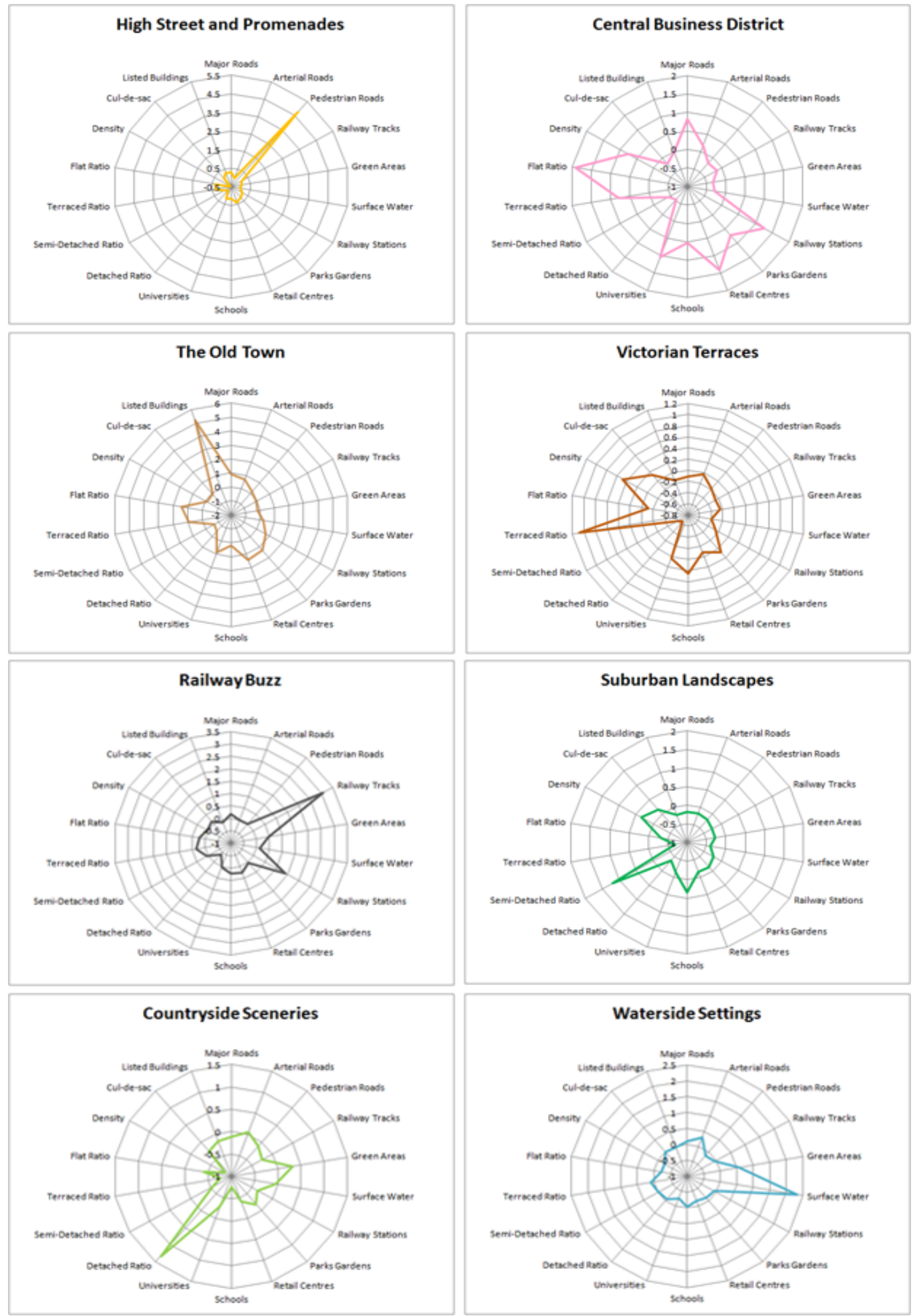

Figure 4. Final cluster results produced by the SOM, with mean attribute centres per cluster. 
This enabled classes to be labelled and the following short descriptions to be created:

\section{High Street and Promenades}

These clearly depicted areas represent the main retail centres of urban regions located along the main commercial streets. This cluster also includes areas with significant pedestrianised street network, especially along seafronts, where a lot of recreational and leisure venues can be found.

\section{Central Business District}

The area often called city centre. Typically, high-rise buildings with a lot of commercial and office spaces, hence the relatively low net population density. These areas have proximity to the majority of public amenities, and have plenty of access vial major roads and railways. For moderate-size cities the title holds true, but in areas such as London they tend to be too expansive to be labelled as central (Figure 6).

\section{The Old Town}

The traditional town centre, usually close by the main high street. It is strongly defined by the amount of registered buildings. Typically, a lot of recreational facilities can be found there, like pubs and restaurants, along with many administrative buildings and some historical major roads. Although it does have a considerable amount of flats, densities remain low, potentially due to refurbishments and change of usage.

\section{Victorian Terraces}

These are typical neighbourhoods with terraced housing, average densities and some access to amenities. It is one of the few morphologies that can be found anywhere.

\section{Railway Buzz}

These areas are dominated by railway tracks and railway stations. They have no other major distinguishing attributes which may suggest that they are actually rather heterogeneous in physical structure.

\section{Suburban Landscapes}

These areas are typically of semi-detached houses, with good access to parks. They tend to be quite distant from town centres. They are primarily residential areas and close to schools. Cul-de-sacs are relatively common, probably because of organized developments and gated communities.

\section{Countryside Sceneries}

These areas are dotted with detached houses, and are located either near or within open countryside. Most rural villages fall into this category, along with some city fringe developments that lie beyond the classic suburbs.

\section{Waterside Settings}

The principal defining attribute of these neighbourhoods is their proximity to surface water such as rivers, canals or sea. Some of these areas are ports, industrial or postindustrial sites. Distinctive infrastructure is arterial roads, i.e. roads wide enough to be used by lorries for the distribution of goods. 


\section{A Comparison of MODUM and OAC}

In order to test whether the Multidimensional Open Data Urban Morphology (MODUM) classification systematically follows the conventional OAC geodemographic classification, we correlate the two sets of output classes via a contingency table. Table 3 shows the frequency distribution of MODUM within OAC 2011. Supergroup 6 - Rural residents seems to be identified fairly well by the morphological features, with a correlation of more than $82 \%$, followed by a small percentage of Waterside Settings and Suburban Landscapes. About half the areas categorized as suburban also fall into this category, which is to be expected taken into account that typologies tend to blend out at the urban edges. The expansive central areas seem to be mainly populated by Supergroup 2 - Cosmopolitans and Supergroup 3 - Ethnicity Central. Moving out of the centre, Victorian Terraces seem to be scattered across three classes, Supergroup 4 - Multicultural metropolitans, Supergroup 7 - Constrained city dwellers and Supergroup 8 - Hard-pressed living. The suburban class is most interesting, as $43 \%$ of the areas classified as suburban is populated by areas identified as Hard-pressed living, while the other $\sim 40 \%$ seems to be acknowledged. Generally speaking, unique classes in the MODUM classification such as the old city centre and railway-heavy areas seem to be equally dispersed among classes. Some further analysis could provide better insight as to why, and even reveal interesting patterns. Figure 5 provides two different sets of maps of the area of Bristol and Leeds, in order to demonstrate the overall pattern relationships between MODUM and OAC.

Table 3. Contingency tables showing frequencies of OAC 2011 classes within MODUM.

\begin{tabular}{|c|c|c|c|c|c|c|c|c|c|}
\hline \multirow[b]{2}{*}{$\begin{array}{l}\text { MODUM Cluster } \\
\text { Description }\end{array}$} & \multicolumn{8}{|c|}{ Output Area Classification 2011 - Supergroup Level } & \multirow[b]{2}{*}{$\begin{array}{c}\text { OA } \\
\text { Amount }\end{array}$} \\
\hline & $\begin{array}{c}1- \\
\text { Rural } \\
\text { residents }\end{array}$ & $\begin{array}{c}2- \\
\text { Cosmopo } \\
\text { litans }\end{array}$ & $\begin{array}{c}3- \\
\text { Ethnicity } \\
\text { central }\end{array}$ & $\begin{array}{c}\text { 4- } \\
\text { Multi- } \\
\text { cultural } \\
\text { metropol } \\
\text { itans }\end{array}$ & $\begin{array}{l}5- \\
\text { Urbani- } \\
\text { tes }\end{array}$ & $\begin{array}{c}6- \\
\text { Suburban } \\
\text { ites }\end{array}$ & $\begin{array}{c}7- \\
\text { Constrain } \\
\text { ed city } \\
\text { dwellers }\end{array}$ & $\begin{array}{c}8- \\
\text { Hard- } \\
\text { pressed } \\
\text { living }\end{array}$ & \\
\hline $\begin{array}{l}1 \text { - Suburban } \\
\text { Landscapes }\end{array}$ & $5.53 \%$ & $2.83 \%$ & $3.38 \%$ & $24.82 \%$ & $23.77 \%$ & $38.97 \%$ & $22.12 \%$ & $43.33 \%$ & 46788 \\
\hline 2 - Railway Buzz & $0.99 \%$ & $10.61 \%$ & $13.50 \%$ & $10.09 \%$ & $8.31 \%$ & $3.08 \%$ & $7.31 \%$ & $5.33 \%$ & 12186 \\
\hline $3-$ The Old Town & $0.25 \%$ & $17.87 \%$ & $5.35 \%$ & $0.58 \%$ & $4.05 \%$ & $0.05 \%$ & $4.76 \%$ & $0.30 \%$ & 2812 \\
\hline $\begin{array}{c}4 \text { - Victorian } \\
\text { Terraces }\end{array}$ & $1.20 \%$ & $14.43 \%$ & $16.56 \%$ & $43.93 \%$ & $24.59 \%$ & $1.79 \%$ & $39.38 \%$ & $34.98 \%$ & 49860 \\
\hline $\begin{array}{l}5 \text { - Waterside } \\
\text { Settings }\end{array}$ & $8.43 \%$ & $5.03 \%$ & $3.56 \%$ & $6.98 \%$ & $12.08 \%$ & $6.73 \%$ & $8.04 \%$ & $8.82 \%$ & 12468 \\
\hline $\begin{array}{l}6 \text { - Countryside } \\
\text { Sceneries }\end{array}$ & $82.45 \%$ & $2.05 \%$ & $0.43 \%$ & $2.91 \%$ & $18.89 \%$ & $47.79 \%$ & $2.14 \%$ & $3.90 \%$ & 3172 \\
\hline $\begin{array}{c}\text { 7- High Street and } \\
\text { Promenades }\end{array}$ & $1.07 \%$ & $6.20 \%$ & $4.28 \%$ & $3.00 \%$ & $4.03 \%$ & $1.50 \%$ & $4.98 \%$ & $2.47 \%$ & 1299 \\
\hline $\begin{array}{c}8-\text { Central Business } \\
\text { District }\end{array}$ & $0.08 \%$ & $40.99 \%$ & $52.94 \%$ & $7.68 \%$ & $4.26 \%$ & $0.09 \%$ & $11.27 \%$ & $0.88 \%$ & 52823 \\
\hline Sum (\%) & 100.00 & 100.00 & 100.00 & 100.00 & 100.00 & 100.00 & 100.00 & 100.00 & 181408 \\
\hline
\end{tabular}

A chi-square test $c^{2}(49,181408)=136280, p<.001$ of the two categorical values shows that the two classifications have a significant relationship between them. We can measure the strength of the association by calculating the Cramer's V value $\varphi_{c}=0.328$, which indicates an important level of association, given that $\varphi_{c}$ can take values between 0 (no association) and 1 (complete association). 

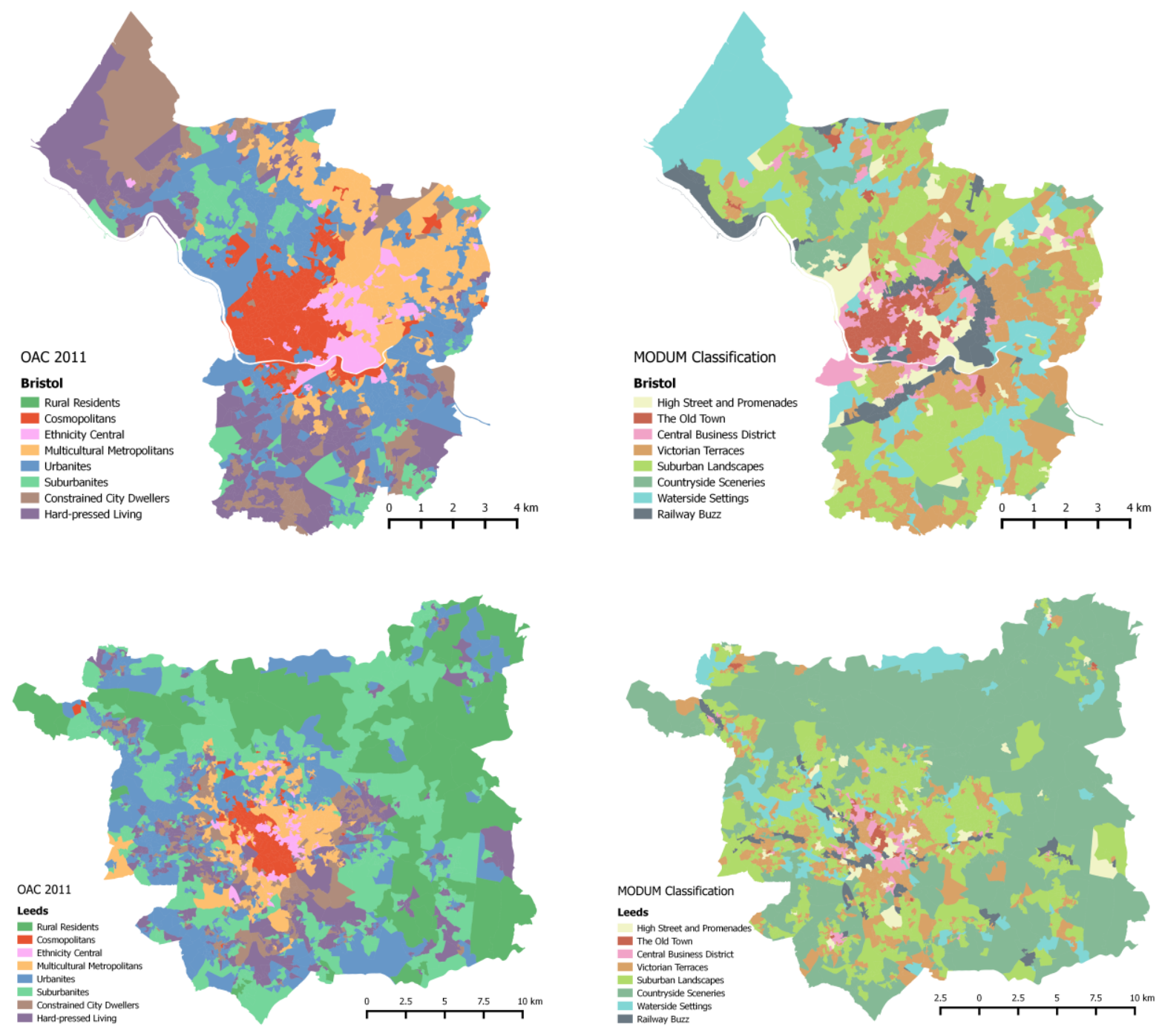

Figure 5. Built environment and socio-spatial patterns for the cities of Bristol (top) and Leeds (below).

The two classifications, MODUM and OAC 2011, share many common locations, especially towards the city centre. In general, axial zones exhibit much more strongly in the morphological classification, while OAC seems to have a more "regionalized" patterning, at least within local extents. 


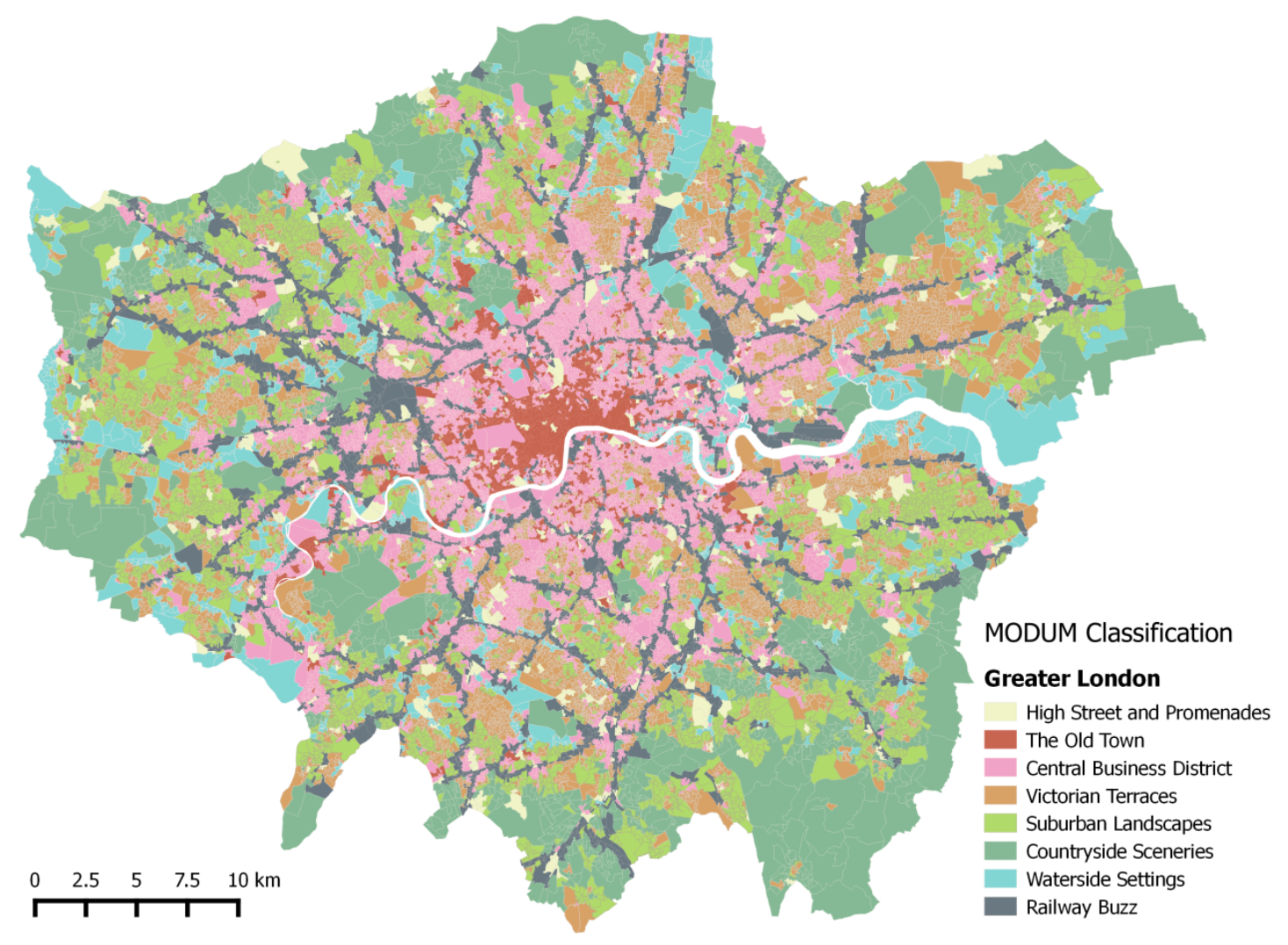

Figure 6. Mapping the MODUM classification for the Greater London Area.

\section{Discussion and Further Research}

The development of MODUM illustrates that the production and analysis of a classification of the built environment using Big and Open Data can offer unique insights into some aspects of geodemographic structure of urban areas. The results capture through the multidimensionality of the data both microscopic and macroscopic identifiers of urban morphology. The classification can be used as input to more complex socio-economic models, increasing robustness. There is strong evidence that residential preference is a significant part related to form of the built environment, suggesting that there is an important dimension to residential decisions beyond homophily. This raises some logical discrepancies in current socio-economic geodemographic classifications; the conceptual "control by aggregation" does not account for these unobserved variables. For instance, one would expect house prices to drop significantly very close to railway tracks. However, these localized phenomena are aggregated in the general context of the area, and thus patterns get "smoothed away", raising some issues about the success of geo-classifications (Voas and Williamson, 2001). While gathering this type of behavioural data would be next to impossible, their outcomes can be observed through peoples' residential decisions on local morphology.

Furthermore, the MODUM classification cannot only enhance socio-economic classifications, and take into account microscopic variation, but also it can also prove useful in itself; it can provide a simplified structure of the physical properties of geographic space that can be used 
to explore correlations with other spatial phenomena, potentially in a variety of applications, from real estate and house prices to health and wellbeing. In a dynamic sense, it can be used by urban planners and investors in the built environment to identify the areas in which the physical preconditions exist for neighbourhood renewal or upscaling.

On the other hand, the classification process described here is very specific to the underlying data and methodology. An inherent disadvantage of all geodemographic classifications is that lack of a single global optimization function during the classification procedure, making them highly susceptible to the operational decisions during the creation process (Openshaw and Gillard, 1978). However, geodemographics are nevertheless still valuable in many circumstances, mainly because they are practicable. Our own classification is easy to use, and offers the ability to append and update data as they become available, while keeping the same model infrastructure intact. In general, it meets the growing need for geodemographic systems that are open and versatile enough to handle the abundance of big data that are currently available.

\section{Acknowledgements}

This research was funded by Economic and Social Research Council grant ES/L011840/1 (Retail Business Datasafe).

\section{References}

Arribas-Bel, D., Nijkamp, P. and Schoelten, H. (2011). Multidimensional urban sprawl in Europe: a self-organizing map approach. Computers, Environment and Urban Systems, 35(4): $265-275$.

Arribas-Bel, D., Schmidt, C. R. (2013). Self-organizing maps and the US urban spatial structure. Environment and Planning B, 2: 362-371.

Barbosa, O., Tratalosa, J.A., Armsworth, P.R., Davies, R.G, Fuller, R.A., Johnson, P. and Gaston, K.J. (2007). Who benefits from access to green space? A case study from Sheffield, UK. Landscape and Urban Planning, 83: 187-195.

Burgess, E.W. (1925). The Growth of City: An introduction to a research project. In R. E. Park, W. Burgess and R. D. McKenzie, (Eds.), The City. Chicago, IL: University of Chicago Press.

CACI (2013). The ACORN user guide: The consumer classification. London: CACI Limited [Accessed April 2014 <URL: http://acorn.caci.co.uk/downloads/Acorn-User-guide.pdf $>$ ].

Colwell, P., Dehring, C. and Turnbull, G. (2002). Recreation demand and residential location, The influence of sensitivity for road traffic noise on residential location: Does it trigger a process of spatial selection?. Journal of Urban Economics, 51:418 - 428.

Dear, M. (2002). Los Angeles and Chicago School: Invitation to Debate. City and Community, 1 (1): 5-32. 
Everitt, B.S., Landau, S., Leese, M., and Stahl, D. (2011). Cluster Analysis, 5th Edn. London: John Wiley \& Sons.

Experian (2014). Mosaic: The consumer classification solution for consistent cross-channel marketing. Nottingham: Experian Limited [Accessed November 2015 <URL: http://www.experian.co.uk/assets/marketing-

services/brochures/mosaic_uk_brochure.pdf $>$ ].

Gidlöf-Gunnarsson, A. and Öhrström, E. (2007). Noise and well-being in urban residential environments: The potential role of perceived availability to nearby green areas. Landscape and Urban Planning, 83: 115-126

Harris, R., Sleight, P. and Webber, R. (2005). Geodemographics, GIS, and Neighbourhood Targeting. Chichester, UK: John Wiley \& Sons.

Hui, E., Chau, C., Pun, L. and Law, M. (2007). Measuring the neighboring and environmental effects on residential property value: using spatial weighting matrix. Building and Environment, 42 (6): 2333-2343.

Janson, C.G. (1980). Factorial social ecology - An attempt at summary and evaluation. Annual Review of Sociology, 6: 433-456.

Kim T., Horner, M.W. and Marans, R.W. (2005). Life Cycle and Environmental Factors in Selecting Residential and Job Locations. Housing Studies, 20 (3): 457-473

Kohonen, T. (2001). Self-organizing maps. Berlin: Springer.

Longley, P.A. (2005). Geographical information systems: a renaissance of geodemographics for public service delivery. Progress in Human Geography, 29 (1): 57-63.

Longley, P.A. and Goodchild, M.F. (2008). The use of geodemographics to improve public service delivery. In J. Hartley, C. Donaldson, C. Skelcher, and M. Wallace, (Eds.), Managing to Improve Public Services. Cambridge, UK: Cambridge University Press, 176-194.

Martin, D., Nolan, A. and Tranmer, M. (2001). The application of zone-design methodology in the 2001 UK Census. Environment and Planning A, 33: 1949-1962.

Openshaw, S. and Gillard, A.A. (1978). On the stability of a spatial classification of census enumeration district data. In P.W.S. Batey (Ed.) Theory and Methods in Urban and Regional Analysis, Pion, London, 101-119.

Ordnance Survey (2015). Open Map - User guide and technical specification v1.4. Crown Copyright.

Parkes, A., Kearns, A. and Atkinson, R. (2002). What makes people dissatisfied with their neighborhoods?. Urban Studies, 39: 2413-2438.

Reibel, M. (2011). Classification approaches in neighborhood research: introduction and review. Urban Geography, 2 (3): 305-316.

Renkow, M. and Hoover, D. (2000). Commuting, Migration, and Rural-Urban Population Dynamics. Journal of Regional Science, 40 (2): 261-287.

Rijnders, E., Janssen, N.A., van Vliet, P.H. and Brunekreef, B. (2001). Personal and outdoor nitrogen dioxide concentrations in relation to degree of urbanization and traffic density. Environmental Health Perspectives, 109 (3): 411-41

Shevky, E. and Bell, W. (1955). Social area analysis. Stanford, CA: Stanford University Press. 
Singleton, A. D. and Longley, P.A. (2009). Geodemographics, visualisation, and social networks in applied geography. Applied Geography, 29 (3): 289-298.

Singleton, A.D. and Spielman, S.E. (2013). The Past, Present and Future of Geodemographic Research in the United States and United Kingdom. The Professional Geographer, 66 (4): 558-567.

Singleton, A.D, Spielman, S.E., and Brunsdon, C. (2016). Establishing a Framework for Open Geographic Information Science. International Journal Of Geographical Information Science, 30 (8): 1507-1521.

Sleight, P. (1997). Targeting customers: How to use geodemographic and lifestyle data in your business. Henley-on-Thames, UK: NTC Publications.

Spielman, S.E. and Singleton, A.D. (2015). Studying Neighborhoods Using Uncertain Data from the American Community Survey: A Contextual Approach. Annals of the Association of American Geographers, 105 (5): 1003-1025.

Spielman, S.E. and Folch, D.C. (2015). Social Area Analysis with Self-Organizing Maps. In A. Singleton and C. Brundson (Eds.), Geocomputation: A Practical Primer. London: Sage.

Spielman, S.E. and Thill, J.C. (2008). Social area analysis, data mining, and GIS. Computers, Environment and Urban Systems, 32 (2): 110-122.

Vale, D.S. (2015). Transit-oriented development, integration of land use and transport, and pedestrian accessibility: combining node-place model with pedestrian shed ratio to evaluate and classify station areas in Lisbon. Journal of Transport Geography, 45:70-80.

Van Ommeren, J., Rietveld, P., and Nijkamp, P. (1999). Job moving, residential moving, and commuting: a search perspective. Journal of Urban Economics, 46: 230-253.

Villeneuve, P.J., Jerrett, M., Su, J.G., Burnett, R.T., Chen, H., Wheeler, A.J. and Goldberg M.S. (2012). A cohort study relating urban green space with mortality in Ontario, Canada. Environmental Research, 115: 51-58

Voas, D. and Williamson, P. (2001). The diversity of diversity: a critique of geodemographic classification. Area, 33 (1): 63-76.

Webber, R.J. (1978). Making the most of the census for strategic analysis. The Town Planning Review, 49 (3): 274-284.

Wehrens, R. and Buydens, L.M.C. (2007). Self- and Super-organising Maps in R: the kohonen package. Journal of Statistical Software, 21(5): 2007. 